\title{
Material selection and structural optimisation for lightweight truck trailer design
}

\begin{abstract}
This paper investigates options for light-weighting truck trailers through a combination of material selection and structural optimisation. Critical chassis design load cases were established, and a parametric finite element model of a typical European-style $13.5 \mathrm{~m}$ long truck trailer built from steel I-beams was developed. The model has been used to show that existing longitudinal steel I-beams could be reduced in weight by $28 \%$ (140 kg) through shape optimisation alone. The model was expanded to analyse holistic composite trailer structures. It showed that up to $67 \%(1,326 \mathrm{~kg})$ of weight could be saved by executing shape and material optimisation in unison. The approach highlights that design through parametric analysis allows for many different structural configurations to be assessed in terms of both mechanical performance and material cost. This facilitates the construction of a theoretical design space of a lightweight chassis, clarifying the weight reduction limits that could be achieved with lightweight materials and structural optimisation. The lightweight trailer chassis designs proposed here are also compared against a portfolio of shorter-term strategies for trailer lightweighting. These strategies are poised to have an increasingly important role in reducing the greenhouse gas emissions of the road freight industry.
\end{abstract}

\section{Keywords:}

Material selection; structural optimisation; composites; truck; trailer.

\section{INTRODUCTION}

Truck trailers used in road freight haulage play a crucial role in logistics and society [1]. The fuel consumption of a road freight vehicle is determined by many factors, such as engine efficiency, driving conditions and vehicle weight. Since empty vehicle weight contributes significantly to overall vehicle weight, it is a contributor to fuel consumption and $\mathrm{CO}_{2}$ emissions. Therefore, using lightweight materials and structural optimisation in the design should be explored in identifying ways to reduce the carbon foot print of the road freight industry as a whole [2, 3].

The most common road freight trailer found in the Europe is the $13.5 \mathrm{~m}$ long curtain side [2] and these types of vehicle are the focus of this study. A schematic overview of this type of trailer is shown in Figure 1, along with the approximate weight of major subcomponents. There are very few regulations on the design of such trailers; hence there is a relatively large scope for innovation within the design process. The exception to this are vehicles and trailers that carry dangerous goods (e.g. petroleum), as these are heavily regulated for safety purposes. The limitations on typical trailers are mostly concerned with outside dimensions, brake behaviour, tyre specifications and lighting requirements, rather than structural performance. This means that the structural design of the trailer is largely unconstrained, creating a window of opportunity for a 'clean-slate' redesign with the aim of significantly reducing empty weight. Replacing subcomponents within existing conventional trailer structures may also prove to be a straightforward and cost-effective way to achieve light-weighting. For example, one option 
is to replace conventional hardwood decking with lightweight composite sandwich panels [4]. Another option is to replace steel and aluminium chassis cross beam members with a glass fibre reinforced polyester (GFRP) composite pultrusion [5].

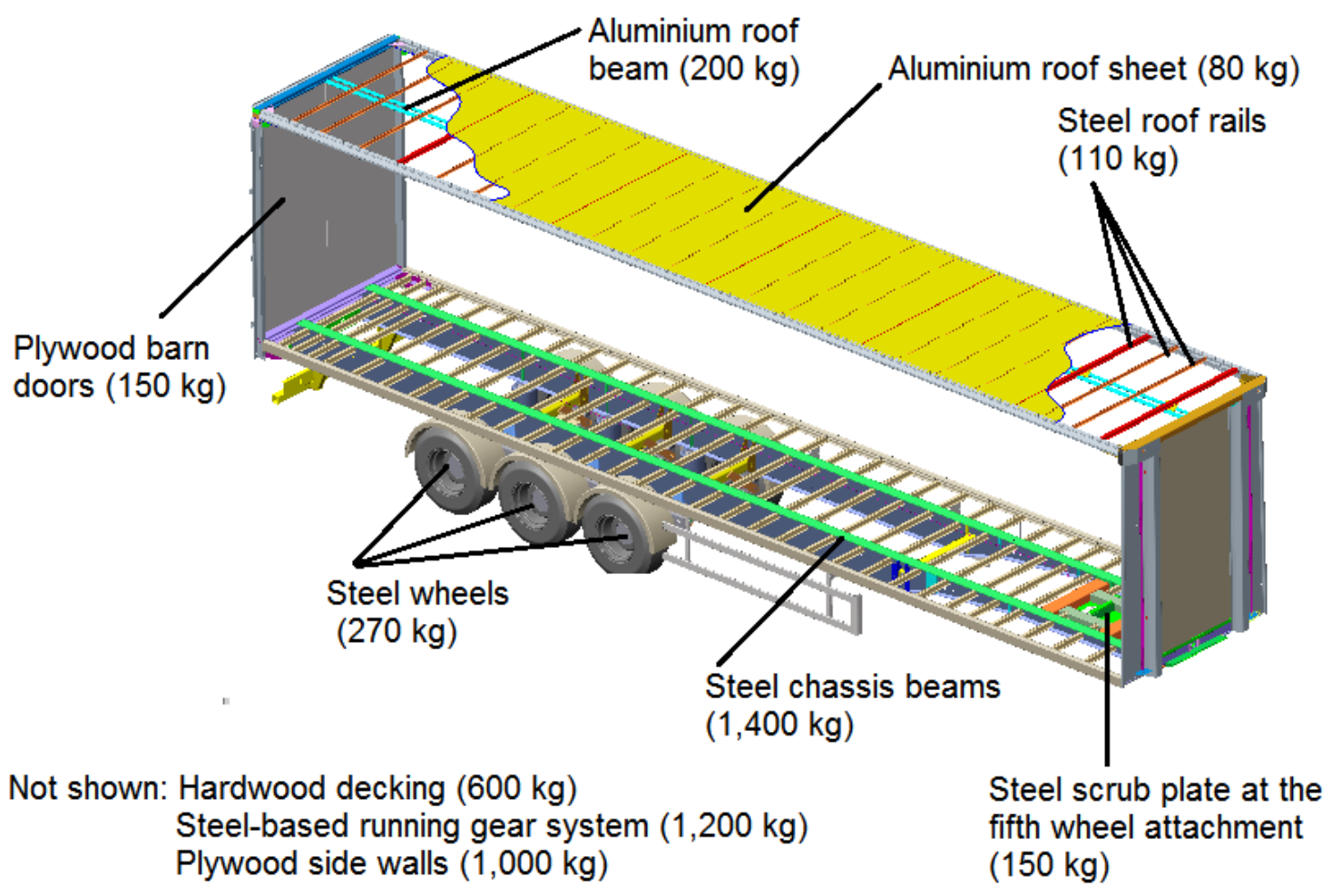

Figure 1. Structural design of a typical $13.5 \mathrm{~m}$ long curtain side trailer and the approximate weight of major subcomponents (courtesy of SDC Trailers). Note that the trailer connects to the truck tractor unit at the fifth wheel attachment point toward the front of the trailer.

Composite materials are also good candidates for use in a 'clean-slate' re-design of the trailer chassis. In recent decades, the realisation of the advantages of replacing metal alloys with composite materials has become prevalent across numerous industries including aerospace, energy, high performance automotive and sporting goods. The broad advantages of composite materials can include: reduced weight, increased corrosion resistance, environmental durability, greater fatigue life and reduced maintenance requirements. However, the increased material and production costs associated with composites often limit their application to high performance, weight-critical applications. As such, the increased cost associated with a holistic composite trailer should be carefully balanced alongside the economic benefits that such a trailer can bring. This is likely to be the reason why previously developed composite trailer prototypes $[6,7]$ have not gained market acceptance.

Another way of reducing trailer chassis weight is via shape optimisation of the conventional ladder-type steel structure and this has been the focus of past research. For example, Kim [8] and Jin Gon [9] developed a novel, lightweight $12.2 \mathrm{~m}$ long trailer frame by applying structural optimisation using finite element (FE) analysis. The design optimisation process used an initial step to obtain an optimum shape topology, followed by a size and shape optimisation step with the Taguchi method to determine detailed dimensions. It was reported that the shape- 
optimised lightweight frame was $24.5 \%$ lighter than the original design and that it had improved bending and torsional rigidities. A major drawback of this approach is in the manufacturability of the complex geometry of the shape-optimised structure compared with the conventional Ibeam ladder-type structure.

The aim of this paper is to investigate the theoretical design space of a lightweight truck trailer chassis in terms of both material and structural optimisation. This approach provides a clarification on the weight reduction limits that could be achieved through various lightweighting strategies. This study builds on previous research on light-weighting European-style truck trailers through fleet case studies, subcomponent replacement and lightweight chassis design $[2,3,4,5,10,11,12]$. The study of composite solutions for trailers presented by the authors in [12] has been extended to include shape optimisation of existing metal I-beams and the application of GFRP pultrusions as chassis beams. By comparing lightweight chassis designs against a portfolio of potential lightweight subcomponent replacements, benefits of different strategies for truck trailer light-weighting can then be thoroughly understood. This can help the road freight industry make informed light-weighting design decisions, which will ultimately aid in meeting greenhouse gas emission reduction targets.

\section{METHODOLOGY}

The methodology behind this study is divided into three main sections. First, the critical load case to be applied in trailer design is identified (Section 2.1). Next, the structural and material numerical optimisation procedures applied in the study are described (Section 2.2). These include; the shape optimisation of existing longitudinal steel chassis I-beams (Section 2.2.1) and the shape and material optimisation of a holistic composite trailer (Section 2.2.2). All optimisation procedures in this study are performed numerically through FE modelling. Finally, materials for light-weighting transverse chassis beams are also investigated (Section 2.3).

\subsection{Critical load cases for trailer design}

Knowledge of critical load cases for lightweight trailer design is an active area of research [13, 14] and beyond the scope of this paper. The critical load cases applied in this study were identified and investigated with the help of industry partners. In order of decreasing importance, the critical load cases include:

1. A fully loaded trailer with a 30 tonne uniformly distributed load (UDL), parked resting on its landing legs and the trailer bogie (i.e. the critical load case).

2. A fully loaded trailer running on the fifth wheel coupling and the trailer bogie.

3. Torsion of a fully loaded trailer during running.

In terms of design constraints, a safety factor of two is often applied in design to account for dynamic loading and fatigue, hence the maximum allowable stresses are generally set to half the yield stress of the high strength low alloy steel used. There are no fixed values for maximum allowable deflection, except for the load case with the trailer parked and resting on its landing legs, where the maximum allowable deflection at the front end of the trailer is 50 $\mathrm{mm}$. With regard to torsional stiffness, how much the chassis twists in service varies a great deal due to its make-up and operating conditions. Industrial partners indicated that torsion is far less critical than the other two cases and that it is specific to operating conditions. Hence it has been neglected in this analysis. Results from previous studies $[13,14]$ also suggest that 
torsion is less critical compared to bending loads. Industry experience has also shown that the static (rather than dynamic) load cases of a fully loaded trailer are the most critical in design. However, dynamic loads and fatigue life are critical considerations in detailed design of components, though these are not in the scope of the present study."

A linear elastic FE analysis was used to benchmark the performance of the conventional steel beam chassis structure (Figure 1). Preliminary modelling showed that the other subcomponents (such as the fifth wheel, bottom rails and landing legs supports) do not contribute significantly to global bending performance of the trailer structure. The simplified ladder-type model used in this study was validated against a full industrial FE model supplied by SDC Trailers Ltd. The full industrial FE model was previously experimentally validated by measuring beam deflections during the two most critical static load cases (i.e. a fully loaded parked trailer and a fully loaded trailer running on the fifth wheel) [15]. The simplified laddertype model produced deflection results within $\sim 5 \%$ of the full industrial FE model.

Displacement contours and stress plots for the simplified ladder-type model were created for the most critical static load case (i.e. a fully loaded parked trailer). The results of the modelling are shown in Figure 2 and Figure 3. For both stiffness and strength, the load case of the fully loaded trailer resting on its landing legs is the most critical. Here the deflection is $50 \mathrm{~mm}$ at the front end of the trailer and $2 \mathrm{~mm}$ at the rear of the trailer. In this load case, the maximum stress in the main longitudinal beams occurs at the goose-neck in the bottom flange and is approximately $40 \%$ of the yield stress, hence within the factor of safety i.e. $50 \%$ of the yield stress. Similar FE calculations were performed for the second load case (i.e. running supported on the fifth wheel). The maximum stress in this case occurs in the main longitudinal beams, occurring toward the front end of the trailer, and is approximately $20 \%$ of the yield stress, well within the margin of safety.

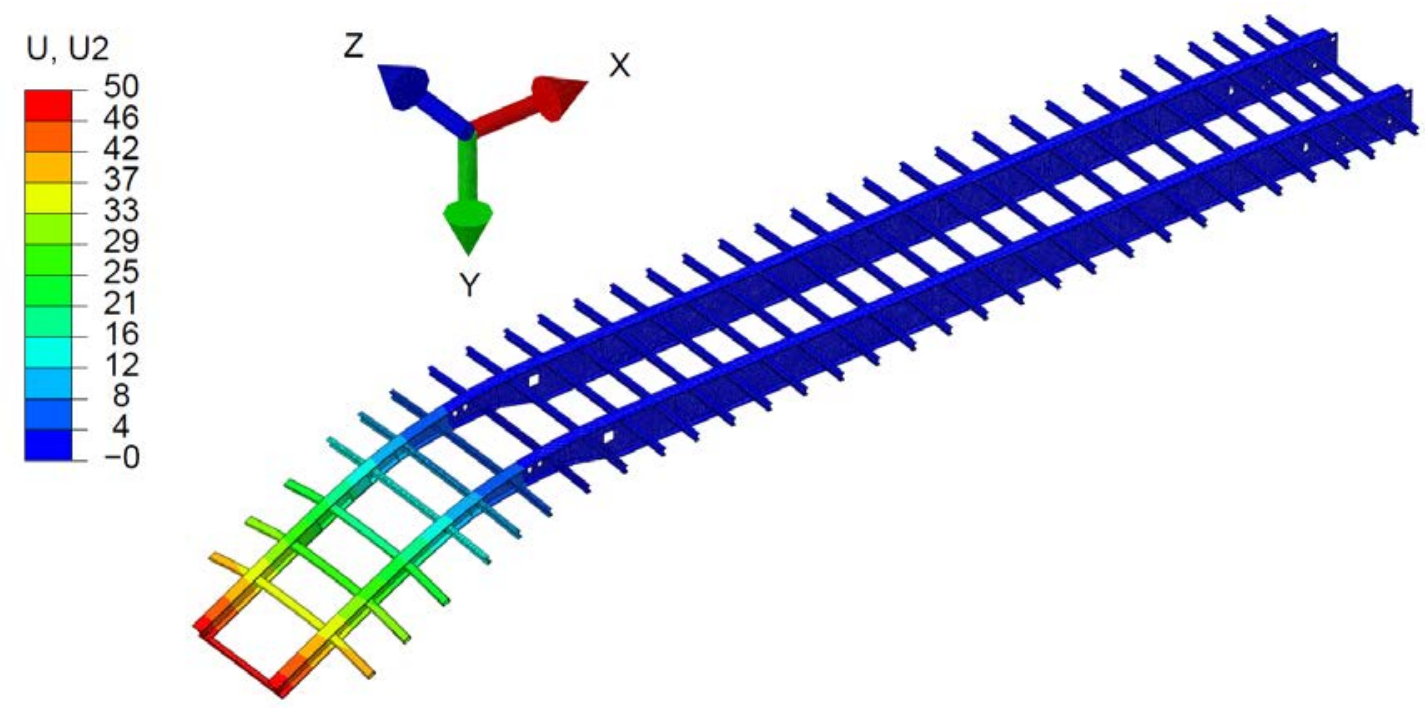

Figure 2. Displacement contour for the load case of resting on landing legs and trailer bogie (30 tonne Uniformly Distributed Load). U2 = displacement in the y-direction in millimetres. The model has fixed restraints at the locations of the bogie and landing legs. A uniformly distributed load of 30 tonnes is applied across the top flange surfaces of the beams. 


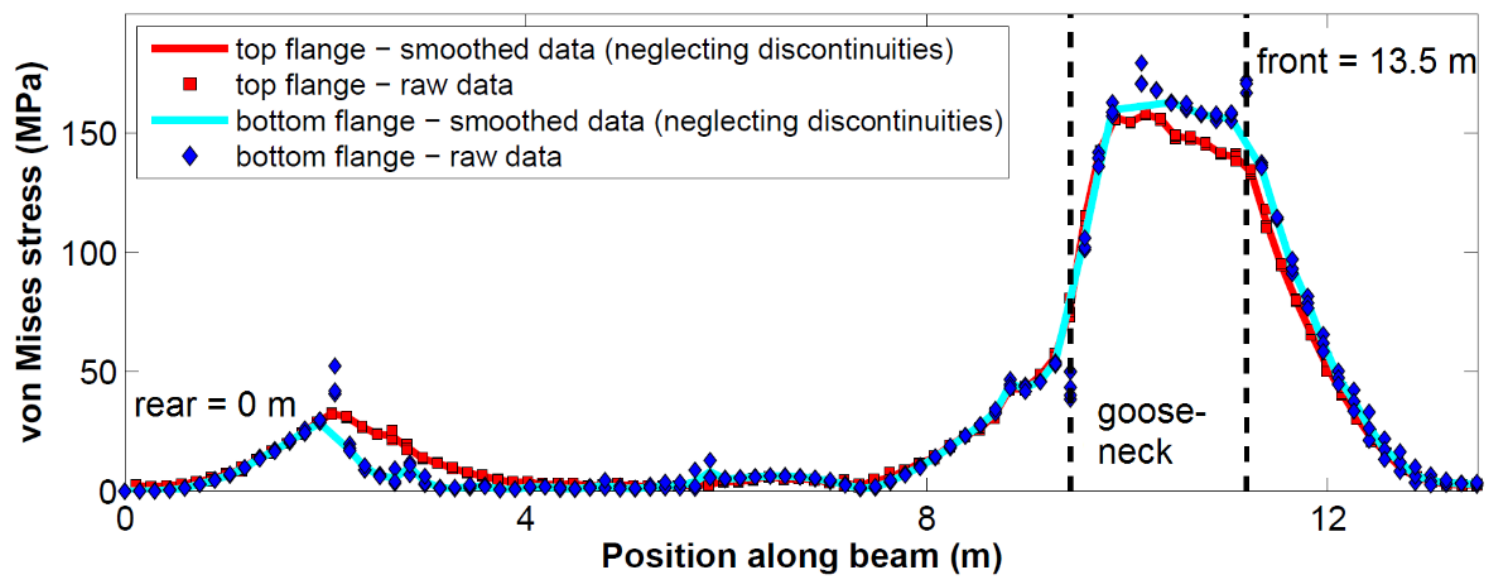

Figure 3. Maximum von Mises stress plot for trailer main beam from the rear $(0 \mathrm{~m})$ to the front $(13.5 \mathrm{~m})$ for the load case of resting on landing legs and trailer bogie (30 tonne UDL).

\subsection{Structural and material optimisation through finite element modelling}

Having established a benchmark for performance for the existing chassis design, in this section we use a finite element analysis to explore optimisation options for the chassis.

\subsubsection{Shape optimisation of existing longitudinal steel chassis I-beams}

To investigate changes that could be potentially implemented to the current ladder-type chassis, a parametric optimisation procedure on the beam component variables listed in Table 1 was first applied to the conventional $13.5 \mathrm{~m}$ steel I-beam, which has bending stiffness properties shown in Figure 4. Details of the optimisation procedure used can be found in [16]; which combines FE analysis of a large number of possible solutions with a graphical optimisation step. The beam was split into front and rear sections as shown in Figure 5. A mesh convergence study was performed, and 135 (100 long) $\mathrm{mm}$ beam elements were chosen as the optimum size for numerical accuracy combined with reasonable computation times. Many geometry variations for both the front and the rear of the beam were investigated to determine their effect on beam mass, stiffness and strength. The full set of geometry variations analysed are shown in Table 1, along with current beam dimensions. The model assumes that the beam is simply supported at the landing legs and the trailer bogie (toward the rear of the beam) and a uniformly distributed 15 tonne line load was applied, as shown in Figure 5. It was assumed that the present height of the beam (shown in Figure 5) is the critical dimension and this remains constant in all simulations, so as to ensure ease of attachment to the tractor unit and a reasonably sized space envelope. 


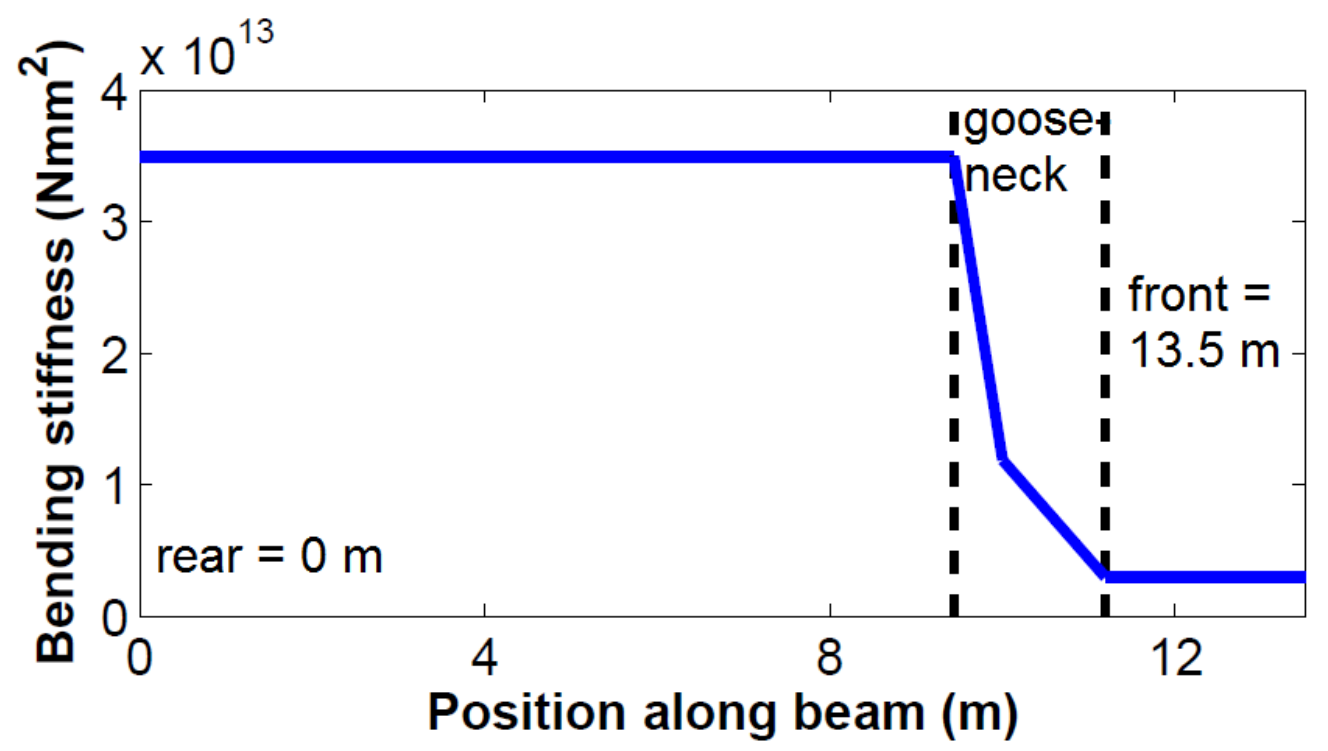

Figure 4. Beam bending stiffness of the main longitudinal trailer I-beam from the rear $(0 \mathrm{~m})$ to the front end $(13.5 \mathrm{~m})$.

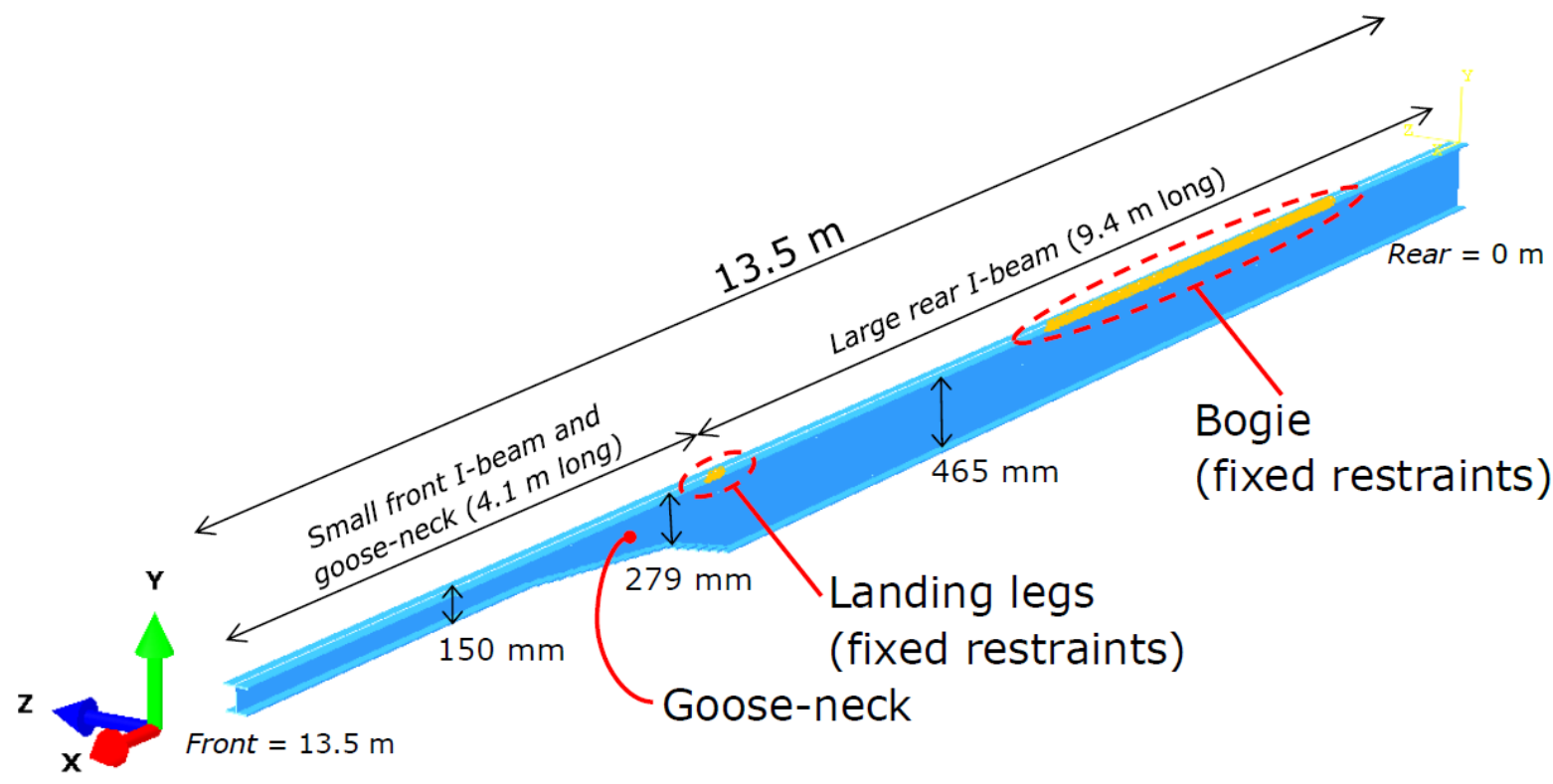

Figure 5. The geometry, uniformly distributed line loading and boundary conditions of the parametric FE model of the main longitudinal I-beam developed in Abaqus. The critical heights along the beam at the front, goose-neck and rear are all shown. Note that the $x$ and $z$ directions indicated correspond to the 1 and 2 material directions, respectively. 


\begin{tabular}{|c|c|c|c|}
\hline Beam component & $\begin{array}{l}\text { Current } \\
\text { dimension } \\
(\mathrm{mm})\end{array}$ & $\begin{array}{l}\text { Modelled dimensions } \\
\qquad(\mathrm{mm})\end{array}$ & $\begin{array}{c}\text { Key for Figure } \\
7\end{array}$ \\
\hline $\begin{array}{l}\text { Rear flange } \\
\text { thickness }\left(t_{r}\right)\end{array}$ & 10 & $\begin{array}{c}2.5 \\
5 \\
7.5 \\
10 \\
12.5 \\
15\end{array}$ & $\begin{array}{l}\text { Orange } \\
\text { Green } \\
\text { Red } \\
\text { Light blue } \\
\text { Purple } \\
\text { Dark blue }\end{array}$ \\
\hline $\begin{array}{l}\text { Front and goose- } \\
\text { neck flange } \\
\text { thickness }\left(t_{f r}\right)\end{array}$ & 10 & $\begin{array}{c}2.5 \\
5 \\
7.5 \\
10 \\
12.5 \\
15\end{array}$ & $\begin{array}{c}\triangle \\
+ \\
\square \\
\times \\
\circ \\
\nabla\end{array}$ \\
\hline Rear flange width & $\begin{array}{c}150 \text { (top) } \\
130 \text { (bottom) }\end{array}$ & $\begin{array}{c}150,250,350,450,550 \\
650,750,850,950,1050 \\
1150,1250\end{array}$ & $\mathrm{n} / \mathrm{a}$ \\
\hline $\begin{array}{l}\text { Front and goose- } \\
\text { neck flange width }\end{array}$ & $\begin{array}{c}150 \text { (top) } \\
130 \text { (bottom) }\end{array}$ & $\begin{array}{c}150,250,350,450,550 \\
650,750,850,950,1050 \\
1150,1250\end{array}$ & $\mathrm{n} / \mathrm{a}$ \\
\hline Rear web thickness & 4 & $2 / 3 \times t_{r}$ & $\mathrm{n} / \mathrm{a}$ \\
\hline $\begin{array}{l}\text { Front and goose- } \\
\text { neck web thickness }\end{array}$ & 6 & $2 / 3 \times t_{f r}$ & $\mathrm{n} / \mathrm{a}$ \\
\hline
\end{tabular}

Table 1. Dimensions of the current typical steel main longitudinal beam and the 5,184 geometry variations analysed with the parametric model in Abaqus.

Since the trailer chassis it is a relatively complex shape, it demands a complicated structural analysis, such as FE analysis. Monroy Aceves et al. [16] developed a methodology for use in the design of composite structures by combining FE analysis with a graphical optimisation step, where a design space is constructed by plotting potential solutions over the design constraints. The design problem specification step is used to define the limits on geometry and potential material combinations. A corresponding set of FE analysis input files were generated using Python. These were then submitted to the solver of FE software Abaqus, and results can then be extracted into a database. This was then read in MATLAB and performance maps can be generated which allow for design constraints to be applied, and thus help to identify optimal solutions within the allowable design space. Note that procedure produces figures that plot thousands of numerically calculated solutions. Hence, it is difficult to identify individual data points on the plots. The coloured data points aid in displaying 'solution clouds' that can aid in identifying trends in the data. While this optimisation approach is computationally expensive as it requires many calculations and iterations, it is an effective way of filling out the design space and identifying optimal solutions within the conflicting design constraints. Indeed, advances in desktop computing power make this form of 'brute-force' analysis more feasible for use. 
The methodology of Monroy Aceves et al. $[16,17]$ was applied here to examine in more detail the potential beam geometries and material combinations suited to a wholly composite trailer. In all scenarios investigated, the critical load case of the trailer resting on its landing legs and bogie was examined. The material properties used throughout the FE analysis are provided in Table 2. These materials were selected to give a broad scope in terms of mechanical properties (in particular stiffness), weight and raw material cost.

\begin{tabular}{lcccccc}
\hline Material & $\begin{array}{c}\boldsymbol{E}_{\mathbf{1}} \\
(\mathbf{G P a})\end{array}$ & $\begin{array}{c}\mathbf{G}_{12} \\
(\mathbf{G P a})\end{array}$ & $\begin{array}{c}\boldsymbol{\sigma}_{1 u} \\
(\mathbf{M P a})\end{array}$ & $\begin{array}{c}\boldsymbol{T}_{12 u} \\
(\mathbf{M P a})\end{array}$ & $\begin{array}{c}\boldsymbol{\rho} \\
\left(\mathbf{k g} / \mathbf{m}^{\mathbf{3}}\right)\end{array}$ & $\begin{array}{c}\text { Cost } \\
(\boldsymbol{E} / \mathbf{k g})\end{array}$ \\
\hline Steel (YS355) & 200 & 80 & 355 & 210 & 7,800 & 0.35 \\
Aluminium & 72 & 27 & 280 & 210 & 2,700 & 1.4 \\
GFRP (continuous fibre) & 23 & 3 & 860 & 83 & 1,800 & 1.2 \\
CFRP (continuous fibre) & 130 & 6 & 1,300 & 62 & 1,550 & 24 \\
\hline
\end{tabular}

Table 2. Material properties used in finite element modelling [18].

To give an indicator of mechanical performance, front and rear beam displacement, as well as failure index within the $13.5 \mathrm{~m}$ longitudinal beam, were all reported. The Tsai-Hill failure criterion was applied to the $13.5 \mathrm{~m}$ longitudinal I-beam to determine the failure index. Because the FE models each use beam elements to model the longitudinal I-beams, the contributions of stress in the transverse 2-direction along the beam were neglected $\left(\sigma_{2}=0\right)$, simplifying the full Tsai-Hill failure criterion to give Eq. (1). The failure index can then be written as a percentage (Eq. (2)). This failure index is applied to all materials to simplify the automation of the analysis. Since the design of the beam is stiffness-driven, the choice of failure criterion does not impact on the final result of the optimisation procedure. However, it should be noted that the von Mises or Tresca yield criteria would be more appropriate for use with metals. Also note that the analysis does not account for local beam buckling, which might invalidate some of the potential solutions.

$$
\begin{gathered}
\left(\frac{\sigma_{1}}{\sigma_{1 u}}\right)^{2}+\left(\frac{\tau_{12}}{\tau_{12 u}}\right)^{2}=1 \\
F I(\%)=\left[\left(\frac{\sigma_{1}}{\sigma_{1 u}}\right)^{2}+\left(\frac{\tau_{12}}{\tau_{12 u}}\right)^{2}\right] \times 100
\end{gathered}
$$

\subsubsection{Shape and material optimisation of a holistic composite trailer}

The optimisation of the longitudinal I-beams can be expanded to include other materials and combined with a structural decking that removes the need for the transverse members in the conventional ladder-type chassis structure. The resulting structure resembles a stiffened panel as shown in Figure 6. Indeed, such a structure lends itself well to the application of composite materials and could also bring significant aerodynamic improvements. This structure was again modelled in Abaqus to investigate the performance of different materials for use in deck and beams. The different materials and geometries considered for use in the longitudinal Ibeams for this scenario are shown in Table 2 and Table 3, respectively. Two decks, differing by an order of magnitude in stiffness, were modelled to illustrate the broad potential of what could be achieved with a structural deck. The I-beam sections were once again modelled with beam elements, while the deck was modelled with a general shell section (with a simplified 
stiffness matrix [D] defined in Appendix 1), that is perfectly connected to the top flanges of the beams. A 30 tonne UDL was applied to the top surface of the deck and the critical load case of the trailer resting on its landing legs and bogie was again examined. The model was meshed in Abaqus with typical planar element size of $100 \mathrm{~mm}$ square, corresponding to 135 beam elements per beam and 3,375 shell elements for the decking. A mesh convergence study was performed, and this mesh was chosen as the optimum size for numerical accuracy combined with reasonable computation times.

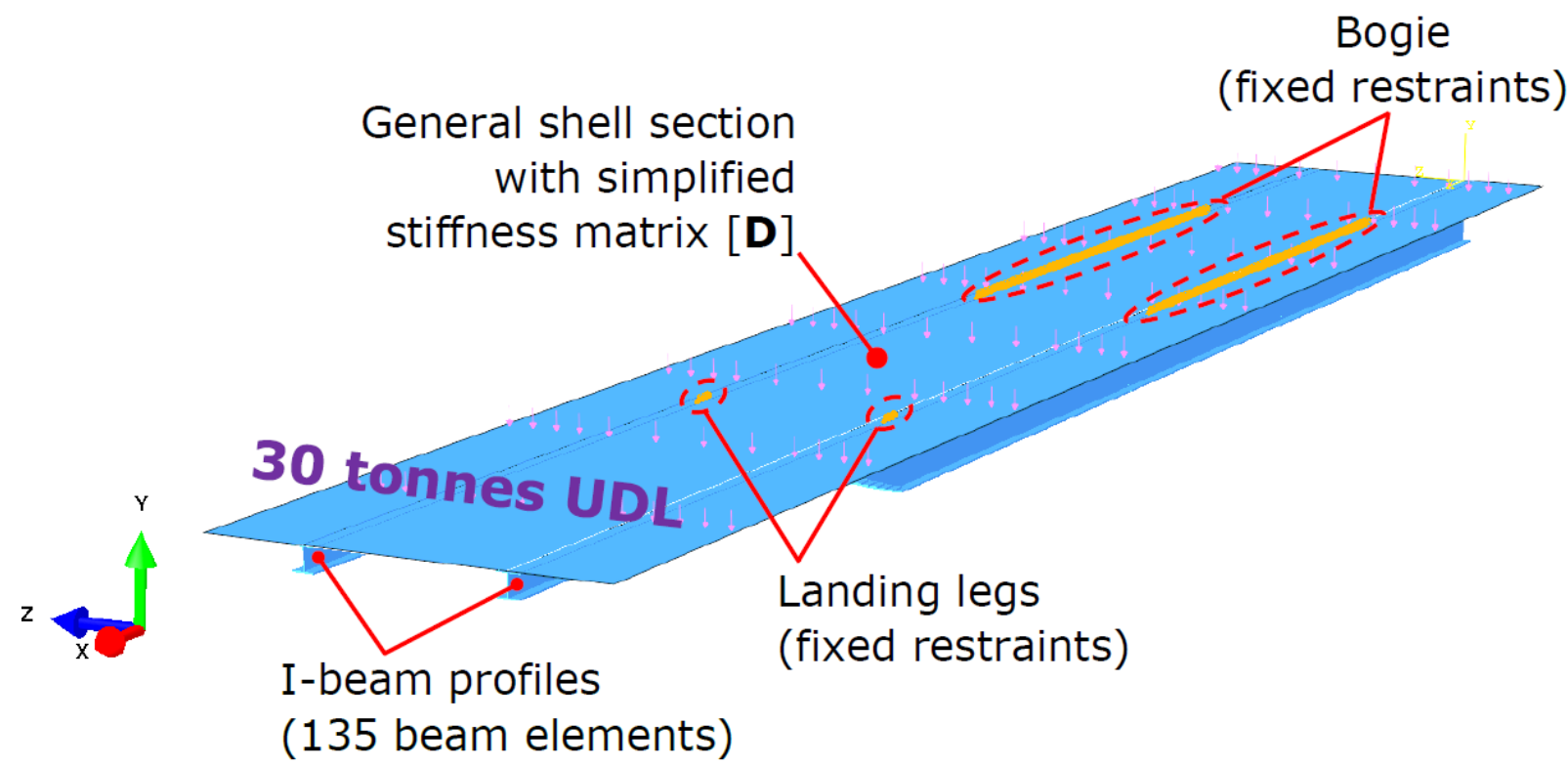

Figure 6. Parameters of the FE model of the composite trailer. I-beams modelled with beam elements and deck modelled with a general shell section with a simplified stiffness matrix [D] (Appendix 1). A 30 tonne uniformly distributed load was applied to the entire top surface of the deck. Note that the $x, z$ and $y$ directions indicated correspond to the 1, 2 and 3 material directions, respectively.

\begin{tabular}{ll}
\hline Beam component & Modelled dimensions $\mathbf{( m m )}$ \\
\hline Flange thickness & $5,10,15,20,25,30,35,40,45,50,55,60$ \\
Flange width & $100,150,200,250,350,400$ \\
Web thickness & $2 / 3 \times$ flange thickness \\
Beam height - rear & $385,425,465$ \\
Beam height - front & 130,150 \\
Beam height - goose-neck & 279 \\
\hline
\end{tabular}

Table 3. Dimensions of the beams (5,184 geometry variations total) investigated with the two different structural decks of stiffness $[\mathbf{D}]_{1}$ and $[\mathbf{D}]_{2}$. Flange width and thickness remains uniform along the length of the beam.

The linear elastic response of the deck shell section is governed by the stiffness matrix [D]. Details of how this stiffness matrix is implement are included in the Appendix 1 . The stiffness matrix $[\mathbf{D}]_{1}$ is representative of a pultruded GFRP decking and it was assumed the mass of this deck is $440 \mathrm{~kg}$ [5]. The stiffness matrix [D] $]_{2}$ is representative of quasi-isotropic CFRP- 
balsa sandwich panel with $5 \mathrm{~mm}$ thick face sheets and a $50 \mathrm{~mm}$ thick core. The total mass of this deck is approximated to be $910 \mathrm{~kg}$. Note that this deck is an order of magnitude stiffer than the pultruded GFRP decking and represents an upper limit of stiffness that could be achieved in practical terms using a lightweight structural deck.

\subsection{Materials for light-weighting transverse chassis beams}

Transverse chassis beams with uniform cross-sections are subcomponents found in a typical ladder-type trailer chassis (Figure 1). They are an ideal candidate for light-weighting through material substitution since they can be fitted into existing trailer designs with longitudinal steel I-beams. This chassis subcomponent replacement strategy is one that could be relatively easily adopted to realise light-weighting in the shorter-term compared with the strategies described in Sections 2.2.1 and 2.2.2.

'Walking-floor' trailers used in bulk haulage have previously been identified as a prime candidate for light-weighting [2]. Rather than steel I-beams for transverse members, they use aluminium transverse U-beams. From a practical standpoint, these trailers seem like a sensible start point for light-weighting with pultruded GFRP sections. In a standard $13.5 \mathrm{~m}$ European-style 'walking-floor' trailer there are typically 29 transverse U-beams weighing 442 $\mathrm{kg}$ total. These trailers also typically operate with a maximum loading of around $30,000 \mathrm{~kg}$. It can be assumed that the flooring over the transverse U-beams distributes the applied load uniformly. This assumption is particularly valid in the case of bulk haulage trailers where payload tends to be spread evenly and is approximately uniform in density. Using these assumptions, and knowing that the transverse beams are supported by two longitudinal members that are $1.2 \mathrm{~m}$ apart (span length $L=1.2 \mathrm{~m}$ ), the maximum bending stress $\sigma$, shear stress $\tau$ and deflection $\partial$, can all be calculated using standard beam theory formulas [11].

The total height of the exiting transverse U-beams $(125 \mathrm{~mm})$ is thought to be the principal geometry constraint for new members to conform to. With this in mind, two different pultrusions were selected from the off-the-shelf sections sold by Fiberline Composites, and their mass and performance compared to conventional aluminium U-beams. The design guidelines for the strength and stiffness of GFRP pultrusions are well defined in the Fiberline Design Manual [19]. If long-term (conservative) values of strength and stiffness are required, then the maximum allowable values for stiffness and strength are as follows:

Maximum allowable bending stress $=75 \mathrm{MPa}$ (safety factor $=3.2$ )

Maximum allowable shear stress $=8 \mathrm{MPa}$ (safety factor $=3.2$ )

Maximum allowable deflection $=\mathrm{L} / 400=1200 / 400=3 \mathrm{~mm}$

\section{RESULTS AND DISCUSSION}

The results of the study are divided into four sections. Firstly, results from the steel I-beam shape optimisation (Section 3.1). Next, results from the combined material and shape optimisation of the trailer. This includes; the influence of trailer decking on the global mechanical performance (Section 3.2.1), as well as the material selection and shape optimisation of a theoretical holistic composite trailer (Section 3.2.2). Following this, results that illustrate the potential use of lightweight materials in transverse chassis beams are presented (Section 3.3). Finally, the results of each of the individual studies are discussed together (Section 3.4) and compared against previous works. 


\subsection{Shape optimisation of existing longitudinal steel chassis I-beams}

The results of the analysis for the steel trailer beam are shown in Figure 7 and the key features of the optimised steel beam (model a) found with this procedure are shown in Table 4. The bottom left quadrants of each graph depict the design envelope of the beam in accordance with the stiffness and strength requirements currently applied. It is evident in Figure 7 that the shape-optimised beam can reduce longitudinal beam mass by approximately $140 \mathrm{~kg} \mathrm{(28 \% ),}$ or $280 \mathrm{~kg}$ total for the two main longitudinal I-beams combined, while maintaining the desired level of mechanical performance. The optimised beam has been achieved by reducing the rear flange width and thickness, increasing the front flange width and maintaining the current level of front flange thickness. The results of Figure 7 confirm that the design of the steel beams for the critical load case is driven by stiffness (characterised by the displacement at the front and rear of the beam) rather than strength (as characterised by the failure index).
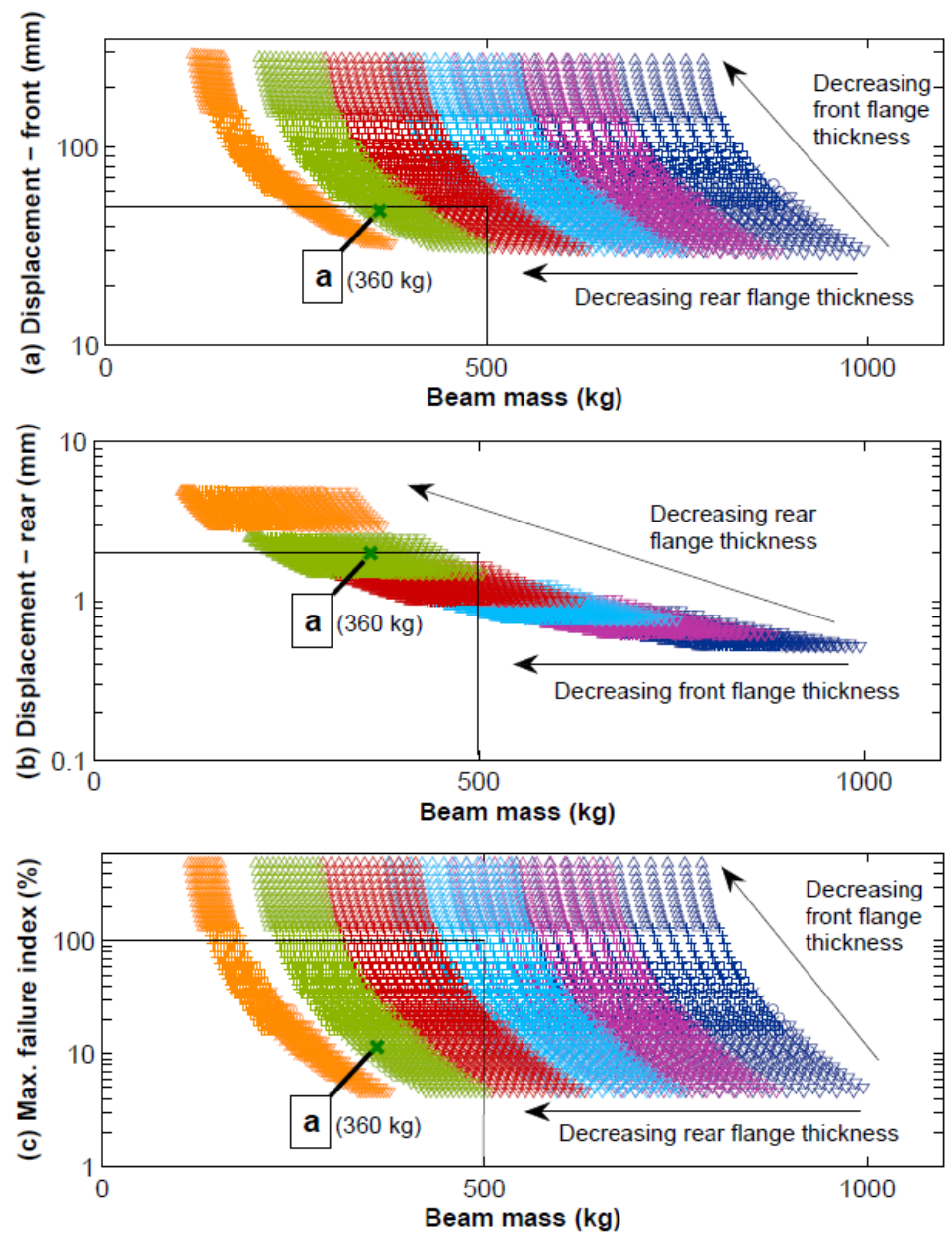

Figure 7. Displacement of the main longitudinal steel (YS355) I-beam at (a) the front end, (b) the rear end and (c) the maximum failure index (Eq. (2)) within the beam, all plotted against beam mass for a 15 tonne uniformly distributed line-load. The design envelope represented by the bottom left quadrant of each graph is established from the mechanical performance of the conventional $500 \mathrm{~kg}$ steel I-beam defined in Section 2.2.1. Model ' $a$ ' is found to be the lightest beam that fits within all three design envelopes. The key for markers is given in Table 1 and Table 4. 


\begin{tabular}{lcccccc}
\hline Model & $\begin{array}{c}\text { Rear flange } \\
\text { thickness } \\
(\mathbf{m m})\end{array}$ & $\begin{array}{c}\text { Rear } \\
\text { flange } \\
\text { width } \\
(\mathbf{m m})\end{array}$ & $\begin{array}{c}\text { Front } \\
\text { flange } \\
\text { thickness } \\
(\mathbf{m m})\end{array}$ & $\begin{array}{c}\text { Front } \\
\text { flange } \\
\text { width } \\
(\mathbf{m m})\end{array}$ & $\begin{array}{c}\text { Total } \\
\text { beam } \\
\text { mass } \\
(\mathbf{k g})\end{array}$ & $\begin{array}{c}\text { Weight } \\
\text { saving } \\
\mathbf{( \% )}\end{array}$ \\
\hline $\mathrm{a}$ & 5.0 & 130 & 10 & 180 & 360 & 28 \\
\hline
\end{tabular}

Table 4. Critical dimensions of the shape-optimised steel (YS355) I-beam, as shown in Figure 7. The height of the beam at the rear, goose-neck and front sections are defined in Figure 5 and the web thickness was assumed to be two thirds of the flange thickness. Note that the total mass of the current typical $13.5 \mathrm{~m}$ steel I-beam is approximately $500 \mathrm{~kg}$.

\subsection{Structural and material optimisation}

\subsubsection{Influence of decking on global mechanical performance}

This section presents results considering a composite structural decking to remove the need for transverse members. The results of the modelling procedure for the most critical design constraint, the front-end displacement of the beams, are shown in Figure 8. It is clear when comparing Figure $8 \mathrm{a}$ and Figure $8 \mathrm{~b}$, that the stiffer CFRP sandwich decking did not significantly increase the mechanical performance of the structure. This is evident in Figure $8 \mathrm{~b}$ where the solution clouds have shifted rightward in comparison to Figure $8 \mathrm{a}$, without having shifted downward enough to include solutions with GFRP based beams, which could bring a substantial cost benefit. This shows that the stiffer decking added a significant amount of weight (approximately $500 \mathrm{~kg}$ ) to the structure, without bringing a clear structural benefit. A CFRP based decking would also be considerably more expensive than a GFRP-based decking. It is clear from this analysis that a lighter, less stiff decking seems to be a more sensible choice. It is evident from Figure 8 that CFRP beams are the best material choice for lightweight, high performance beams. This is apparent through the fact that models with CFRP beams are the most prominent solutions to feature in the light and stiff design envelopes depicted by the boxes in the bottom left quadrants of Figure 8. Certainly, CFRP composite beams would work well in conjunction with a composite decking, with single shot manufacturing options being a possibility. Composite beams are explored in greater detail in Section 3.2.1. 
(a) Pultruded GFRP deck

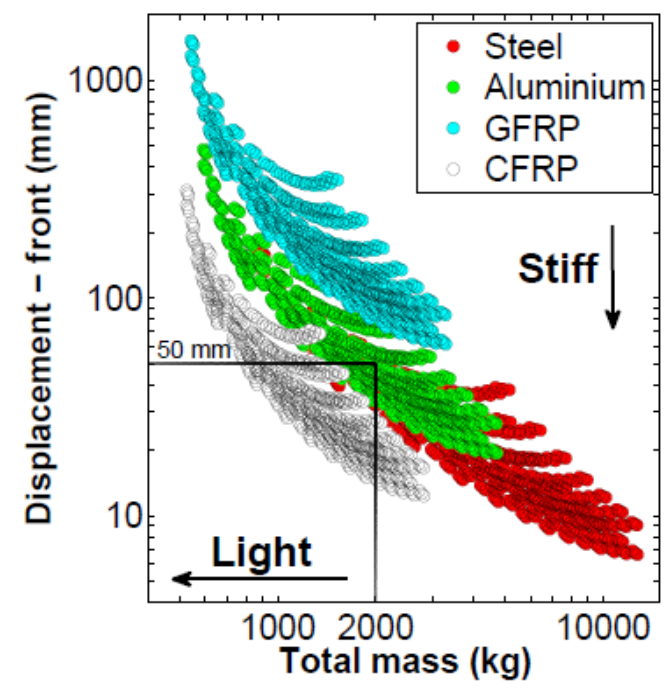

(b) Sandwich panel deck (CFRP-balsa)

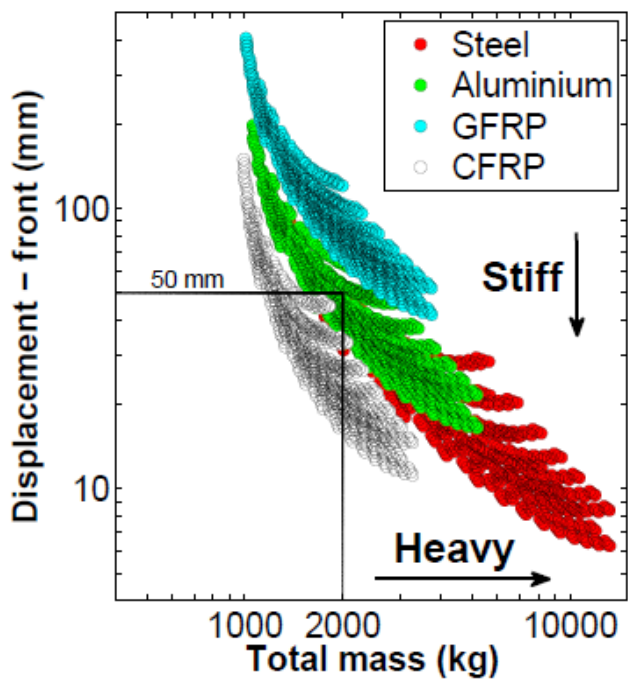

Figure 8. Front end displacement (with 30 tonne UDL) of the longitudinal I-beams, plotted against total chassis mass (combined mass of the beams and decking).

(a) Deck shell stiffness matrix [D] $]_{1}$ : Pultruded GFRP decking $(440 \mathrm{~kg})$.

(b) Deck shell stiffness matrix [D]2: CFRP-balsa sandwich panel decking (910 kg).

Note that the total mass of the corresponding current typical steel chassis and hardwood decking is approximately $2,000 \mathrm{~kg}$.

\subsubsection{Shape and material optimisation of a holistic composite trailer}

Additional modelling was performed to examine in more detail composite beam design for use in conjunction with GFRP-based structural decking (440 kg and shell stiffness matrix [D $\left.]_{1}\right)$. It was evident from the results of Section 3.2 that CFRP beams are the most advantageous in terms of balancing weight reduction and mechanical performance. However, their significantly higher raw material cost needs to be taken into consideration. To this end, hypothetical glasscarbon beams were modelled, whereby the rear of the beam is modelled as GFRP, while the front end of the beam was modelled as CFRP. This strategy reduces total weight and raw material costs down, while maintaining mechanical performance. This kind of mixed glasscarbon structure could be difficult and costly to achieve with current composite manufacturing technologies; however, it may become more feasible with future advancements. The geometries considered for use in the I-longitudinal beams for this scenario are shown in Table 5 . 


\begin{tabular}{lcc}
\hline Beam component & $\begin{array}{c}\text { Modelled } \\
\text { dimensions }(\mathbf{m m})\end{array}$ & Key for Figure 10 \\
\hline Rear flange thickness $\left(t_{r}\right)$ & 2.5 & Orange \\
& 5 & Green \\
Red \\
Light blue \\
& 7.5 & Purple \\
& 10 & Dark blue \\
\hline Front and goose-neck flange thickness $\left(t_{\text {fr }}\right)$ & 12.5 & $\triangle$ \\
& 15 & + \\
& 5 & $\square$ \\
& 10 & $\times$ \\
& 15 & \\
& 20 & $\mathrm{n} / \mathrm{a}$ \\
\hline Rear flange width & 25 & \\
& 30 & $\mathrm{n} / \mathrm{a}$ \\
& $150,250,350,450$, & \\
\hline Front and goose-neck flange width & $550,650,750,850$, & $\mathrm{n} / \mathrm{a}$ \\
\hline Rear web thickness & $950,1050,1150$, & \\
\hline Front and goose-neck web thickness & 1250 & \\
\hline
\end{tabular}

Table 5. Dimensions of the lightweight composite beams (5,184 total geometry variations) modelled in conjunction with the structural decking defined by the simplified stiffness matrix $[\mathrm{D}]_{1}$.

The results for the modelling and optimisation of the composite chassis are presented in Figure 9 and Table 6, respectively. The current stiffness requirements (assumed to be $50 \mathrm{~mm}$ and $2 \mathrm{~mm}$ of deflection at the front and rear end, respectively) are plotted as horizontal lines in Figure 9a and Figure 9b. It is apparent from Figure 9 that the shape-optimised CFRP beams combined with GFRP decking (model $A$ ) could reduce the overall chassis mass by approximately $60 \%(1207 \mathrm{~kg})$, while still meeting the current design constraints for stiffness and strength. With the current conventional design constraints, the shape-optimised glasscarbon beams with GFRP decking (model B) could only reduce overall chassis mass by approximately $19 \%(370 \mathrm{~kg})$ and would have significantly larger dimensions, as shown in Table 6. However, assuming that the maximum allowable rear end displacement could be relaxed from $2 \mathrm{~mm}$ to $4 \mathrm{~mm}$ (as shown in Figure 9b), shape-optimised glass-carbon beams (model B1) become significantly more attractive, as their weight saving potential rises from $19 \%$ to $47 \%(940 \mathrm{~kg})$. By restricting the use of CFRP to the front end only, the overall raw material cost associated with the chassis becomes significantly lower than in the case when CFRP is used in the entire beam (Figure 9d). The largest weight reduction potential was observed in the chassis with shape-optimised CFRP beams with an allowable rear displacement of $4 \mathrm{~mm}$ (model A1), as shown Figure 9. In this case, weight is reduced by approximately $67 \%$ (1326 kg). 


\begin{tabular}{ccccccc}
\hline Model & $\begin{array}{c}\text { Rear beam } \\
\text { material }\end{array}$ & $\begin{array}{c}\text { Rear } \\
\text { flange } \\
\text { width } \\
\mathbf{( m m}\end{array}$ & $\begin{array}{c}\text { Front beam } \\
\text { material }\end{array}$ & $\begin{array}{c}\text { Front } \\
\text { flange } \\
\text { width } \\
\mathbf{( m m}\end{array}$ & $\begin{array}{c}\text { Total } \\
\text { mass (kg) }\end{array}$ & $\begin{array}{c}\text { Weight } \\
\text { saving } \\
\mathbf{( \% )}\end{array}$ \\
\hline A & Carbon fibre & 450 & Carbon fibre & 650 & 793 & 60 \\
A1 & Carbon fibre & 150 & Carbon fibre & 750 & 674 & 66 \\
B & Glass fibre & 1,150 & Carbon fibre & 650 & 1,630 & 19 \\
B1 & Glass fibre & 850 & Carbon fibre & 850 & 1,060 & 47 \\
\hline
\end{tabular}

Table 6. Key features of optimised composite trailer chassis with pultruded glass fibre decking.
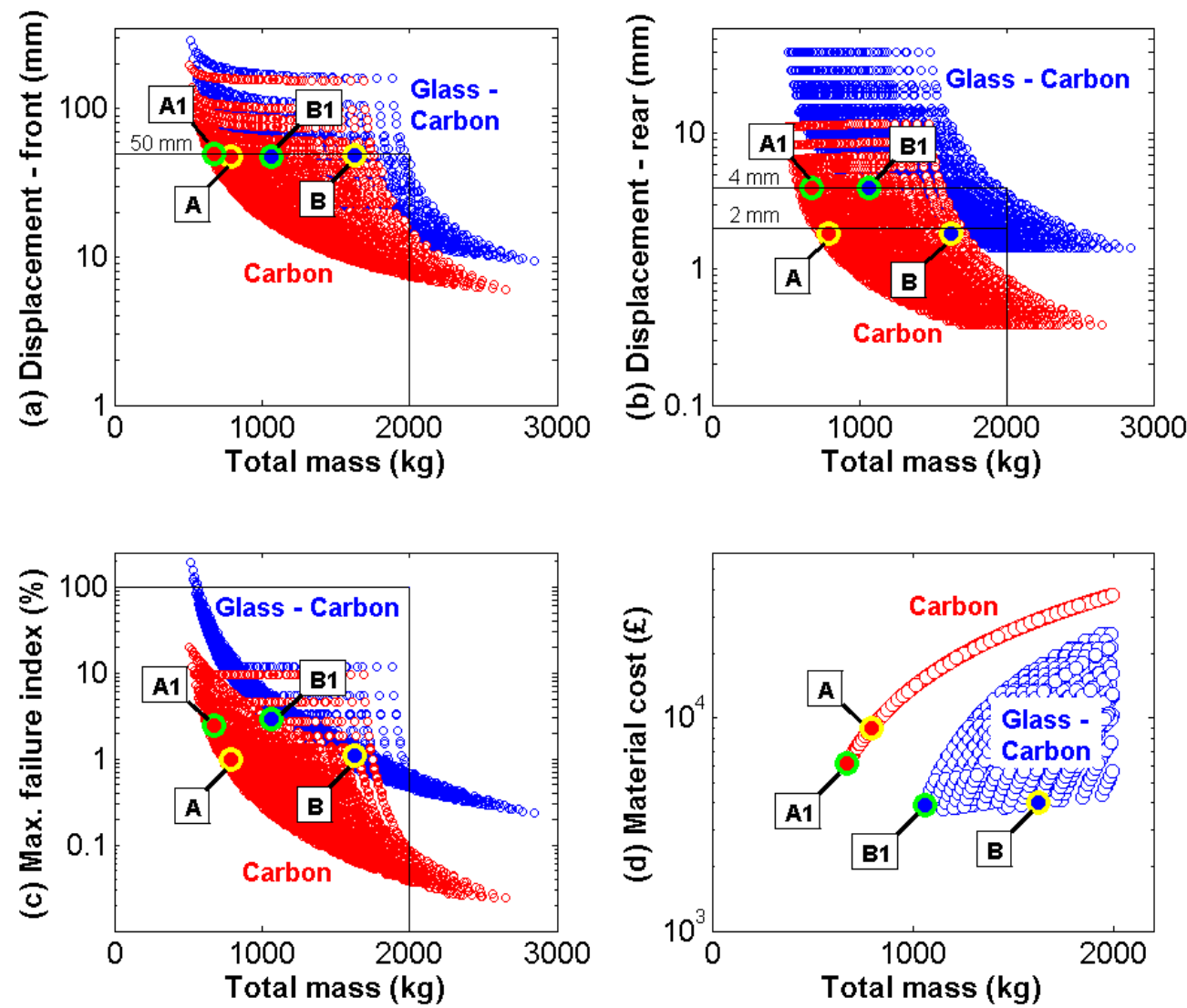

Figure 9. Performance plots of the composite chassis with a 30 tonne UDL applied to the top surface of the decking. (a) Displacement of the main longitudinal beam at the front end. (b) Displacement of the main longitudinal beam at the rear end. (c) Maximum failure index within the beam (Eq. (2)). (d) Total raw material cost. Note: All models use pultruded GFRP decking $(440 \mathrm{~kg})$. Red markers indicate CFRP beams and blue markers indicate GFRP at the rear of the two main longitudinal beams and CFRP at the front end of the beams. Further details of models A, A1, B, and B1 are provided in Table 6.

Similar trends for beam displacement as a function of beam geometry are seen for composite beams (Figure 10), as were seen for steel beams (Figure 7). Decreasing the rear flange thickness significantly reduces the total chassis mass. In practice, detailed design of thin members would be required to avoid other failure mechanisms such as local buckling failure. 
While the results from the optimisation procedure might vary for other load cases (e.g. buckling), it can be expected that a weight optimised design could still be achieved by stiffening critical areas of the structure with CFRP.
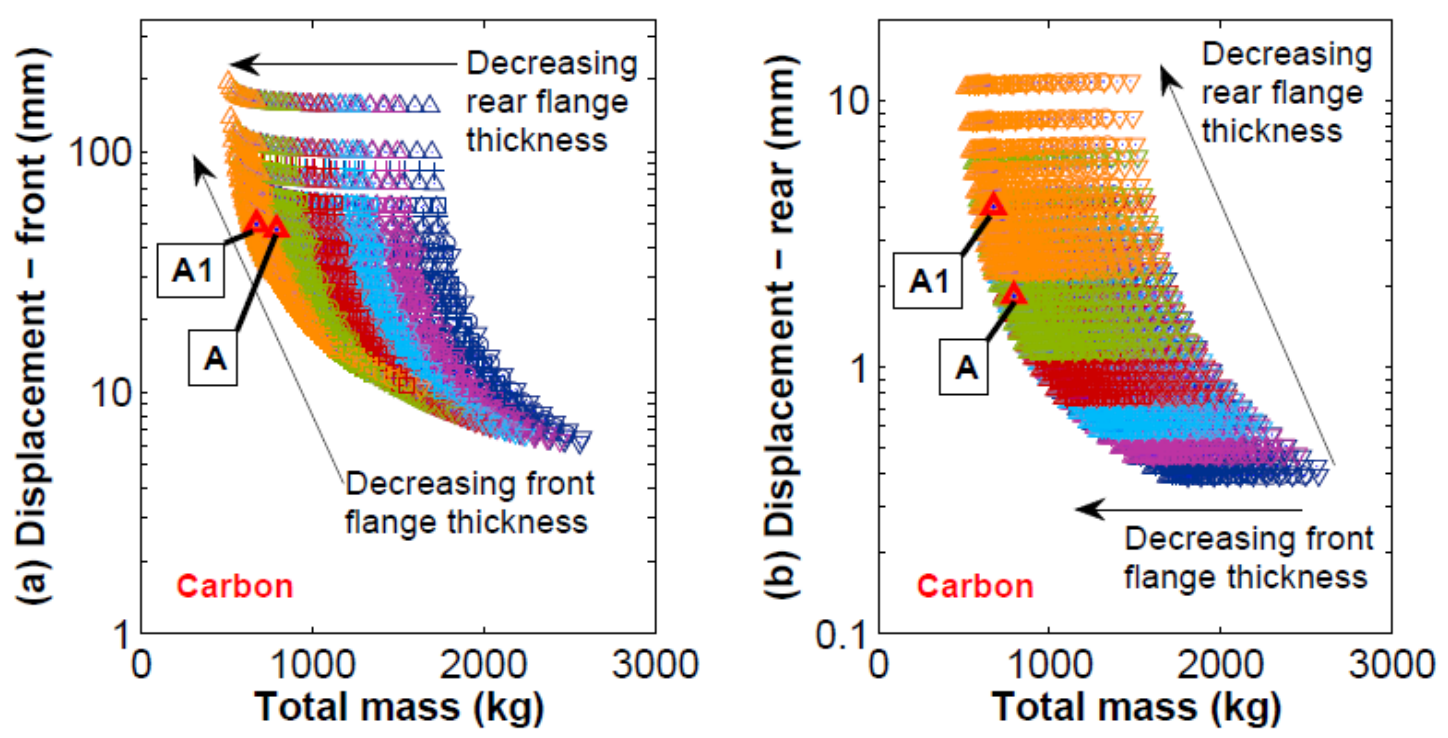

Figure 10. Trends in displacement performance plots (Figure 9a and Figure 9b) for the composites chassis with CFRP I-beams. (a) Displacement of the main longitudinal beam at the front end. (b) Displacement of the main longitudinal beam at the rear end. Key see Table 5 and Table 6.

\subsection{Materials for light-weighting transverse chassis beams}

A comparison of aluminium transverse U-beams used in conventional 'walking-floor' trailers and two off-the-shelf GFRP pultrusions is shown in Table 7. It is evident that the GFRP pultrusions entail higher levels of deflection than the aluminium members. However, the deflection, like the bending stress and shear strength, are all within the maximum allowable values defined by the design guidelines. The exception is the bending stress of the rectangular profile pultrusion, which is slightly higher than the recommended limit. This suggests that the square pultruded GFRP profile would be the safest choice and these could bring a total weight saving of approximately $100 \mathrm{~kg}$. However, despite their less desirable mechanical performance, the rectangular profile could bring a total weight saving of almost $200 \mathrm{~kg}$.

\begin{tabular}{lcccc|ccc}
\hline & & & & \multicolumn{3}{c}{ Applied load = 30,000 kg } \\
\hline $\begin{array}{l}\text { Profile } \\
\text { type }\end{array}$ & Material & $\begin{array}{c}\text { Dimensions } \\
\mathbf{h} \times \mathbf{~ b ~ x ~ t ~} \\
\mathbf{( m m})\end{array}$ & $\begin{array}{c}\text { Weight } \\
\mathbf{( k g / m )}\end{array}$ & $\begin{array}{c}\text { Total } \\
\text { weight } \\
\mathbf{( k g )}\end{array}$ & $\begin{array}{c}\boldsymbol{\sigma} \\
(\mathbf{M P a})\end{array}$ & $\begin{array}{c}\boldsymbol{\tau} \\
\mathbf{( M P a})\end{array}$ & $\begin{array}{c}\partial \\
(\mathbf{m m})\end{array}$ \\
\hline $\mathrm{U}$ & Aluminium & $125 \times 65 \times 10$ & 6.35 & 442 & 72 & 3.7 & 0.6 \\
Square & GFRP & $120 \times 120 \times 6$ & 4.95 & 345 & 61 & 3.1 & 1.6 \\
Rectangle & GFRP & $140 \times 60 \times 6$ & 3.65 & 254 & 83 & 4.9 & 1.9 \\
\hline
\end{tabular}

Table 7. Comparison of the mechanical performance of two pultruded GFRP sections to the aluminium U-beams used in conventional 'walking-floor' trailers. 


\subsection{Discussion}

The strategies for light-weighting truck trailers can be split into two broad categories; lightweight solutions for specific subcomponents and adopting a 'clean-slate' design approach for the whole trailer. The findings of this study predominately relate to the latter, and other studies from the authors have focused on the former $[4,5,12]$. A summary of the weightsaving benefits of both approaches is shown in Figure 11. It shows that by adopting multiple subcomponent replacement strategies, significant weight reductions can be achieved without the need for a complete re-design of the trailer chassis. This has been the approach adopted in a recent Innovate UK project whereby the empty weight of a double-deck trailer was reduced by approximately $2,000 \mathrm{~kg}$ through subcomponent replacement alone [20]. Trailer decking and side walls are two examples of trailer subcomponents that are particularly good candidates for light-weighting since they can be fitted relatively easily around existing structures and can bring significant weight reductions [4].

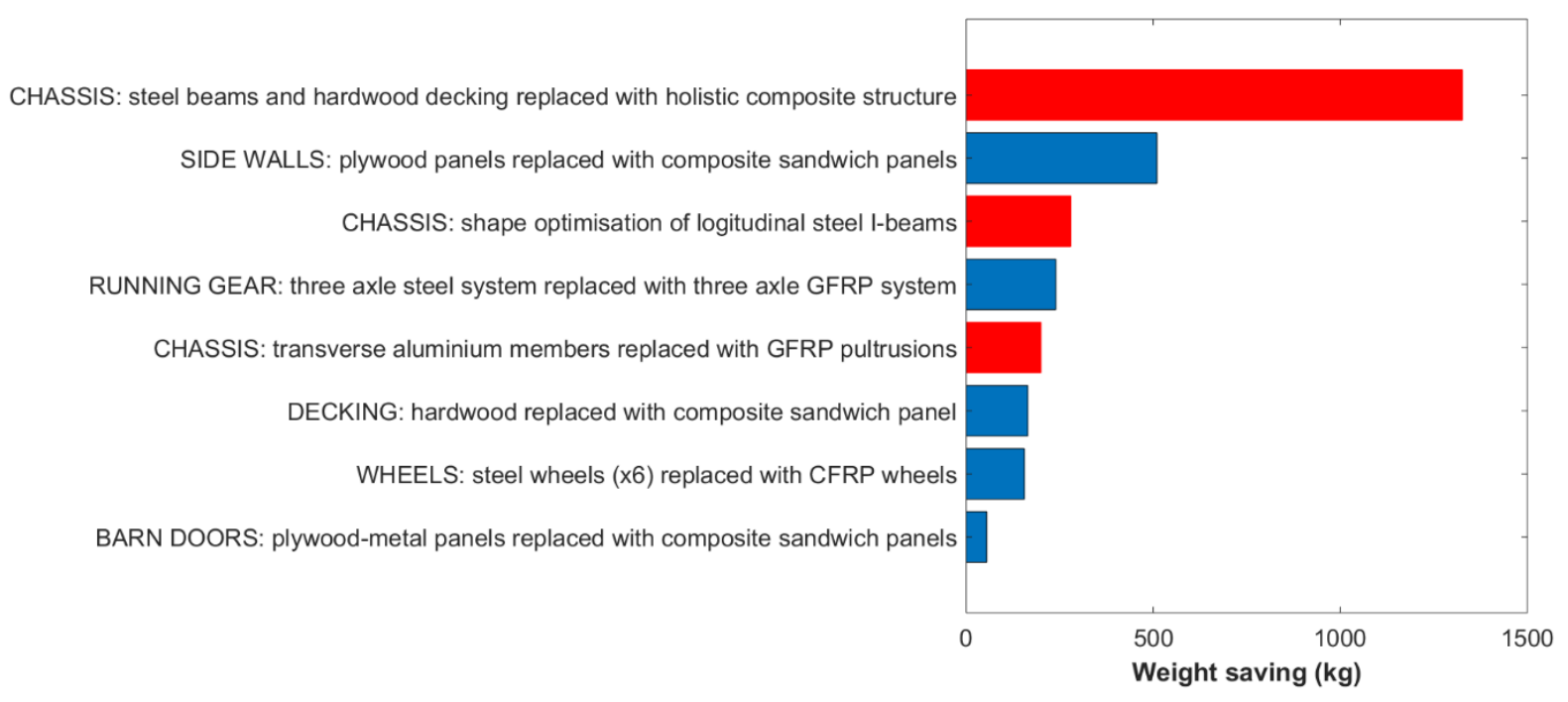

Figure 11. Summary of estimates of potential weight saving opportunities from various lightweighting strategies for a $13.5 \mathrm{~m}$ European-style trailer. Red bars indicate results developed within the present study, blue bars represent findings from previous studies $[2,3,4,5,10$, 11, 12].

For light-weighting strategies to reach the point where they can be implemented in industry, they need to be largely driven by cost. Materials costs alone are thought to represent at least half of the total production costs of a trailer. It is believed that the most successful lightweight solutions will strike a balance between cost, mechanical performance and weight reduction. To this end, Ashby maps (Figure 12) that are traditionally used for material selection in mechanical design, can also aid in understanding the best material choices for the trailer chassis. Figure 12a confirms that a CFRP based chassis is the best choice (highest specific Young's modulus and specific yield strength) when raw material cost is not taken into consideration. Figure 12b shows that low alloy steels (like those currently used) are a top candidate when raw material costs are taken into consideration. 


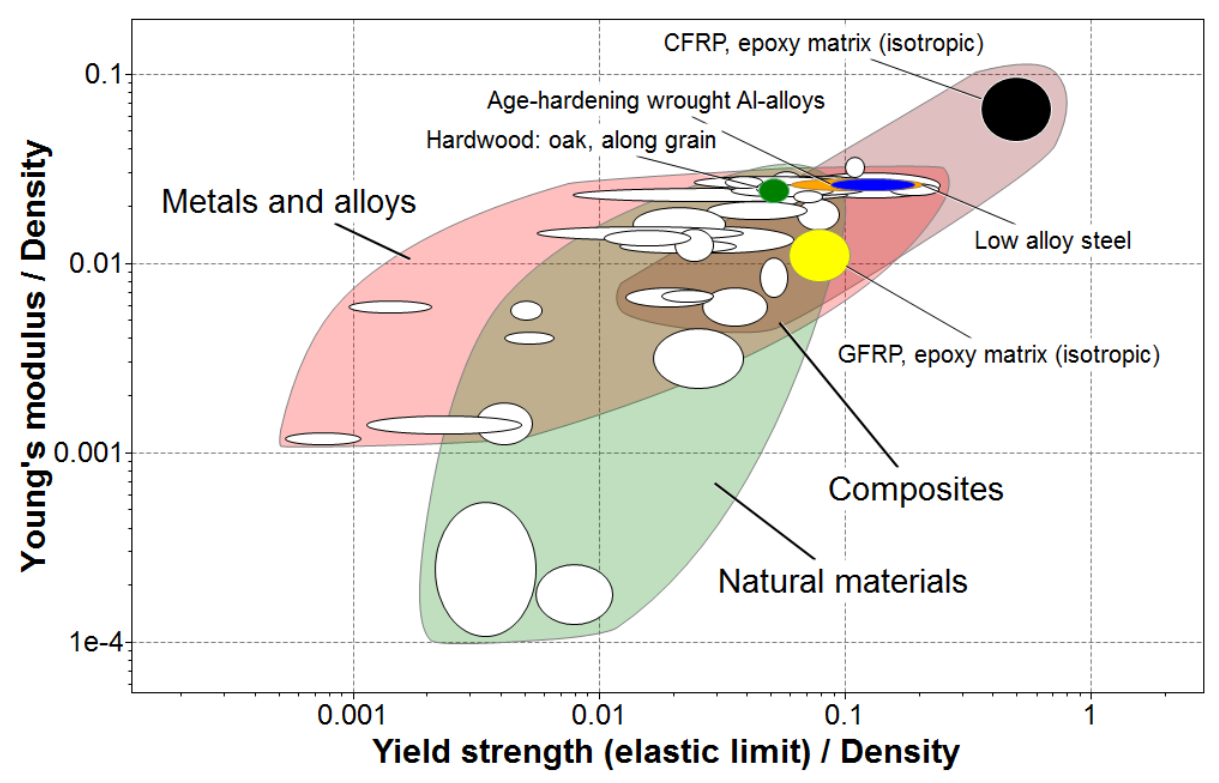

(a)

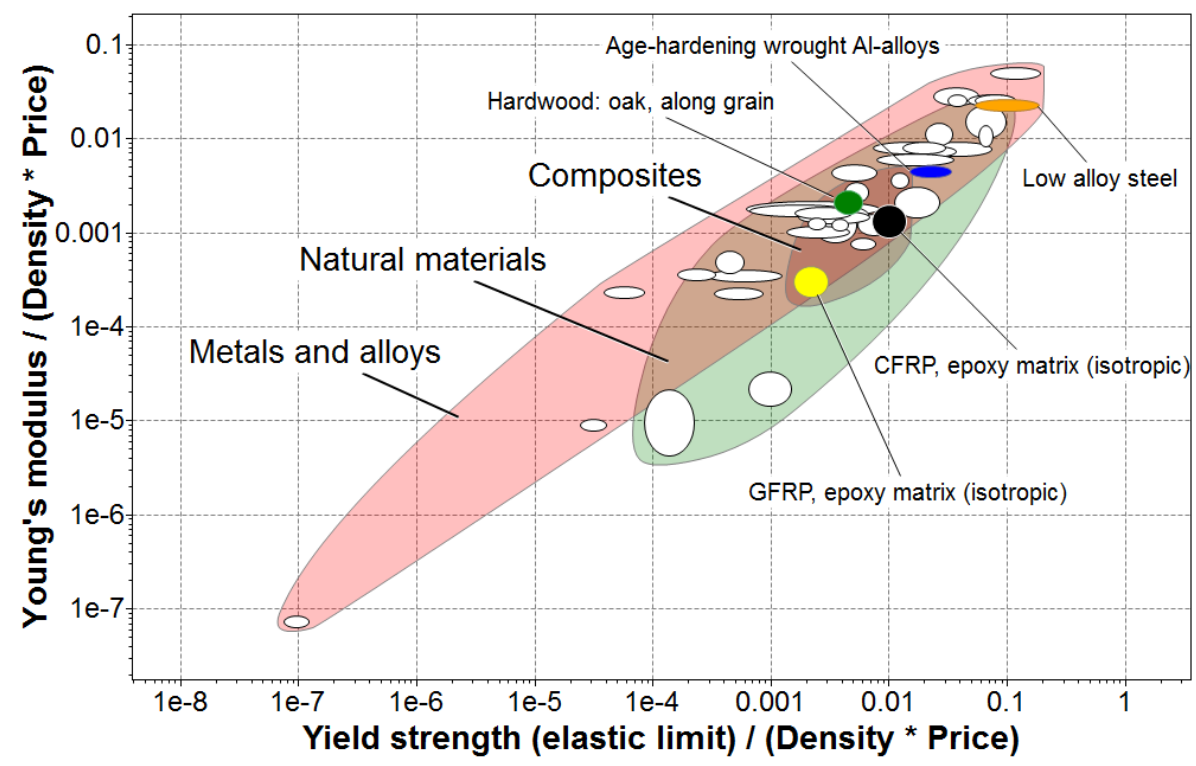

(b)

Figure 12. Ashby maps showing the specific Young's modulus and yield strength for engineering materials used in truck trailer design; (a) without raw material price taken into consideration and (b) with raw material price taken into consideration [18].

Adopting a 'clean-slate' design approach will allow for the full benefits of continuous fibre composite materials to be realised and will also allow for the integration of composite materials with other emerging technologies such as active steering of trailer wheels and aerodynamic fairings $[2,21,22]$. The integration of aerodynamic and structural functions can help achieve weight reduction and aerodynamic improvement simultaneously. Moreover, the directional nature of continuous fibre composites can be exploited to increase structural reinforcement at areas of high stress concentration, such as the goose-neck, and remove mass in parts of the 
structure are not significantly loaded. To achieve this, more detailed knowledge and empirical data of various trailer load cases is needed.

Observations from previous lightweight composite trailers that have adopted a 'clean-slate' design suggest that the major drawback in this approach is the increased raw material and production costs associated with continuous fibre composites. For example, resin transfer moulding (RTM) used in fabrication of a GFRP-based trailer is very unlikely to be taken up by existing trailer manufacturers. Adopting this process would require significant investment in new equipment and facilities, as well as extensive staff re-training. Similar issues apply for CFRP-based trailers which may require an autoclave to cure components. Perhaps the most financially viable way of achieving a composite redesign is to outsource the manufacture of composite components and then integrate these components in existing trailer assembly lines.

Pultrusion processing is one alternative technique that could be employed to avoid tedious manufacturing processes, such as hand lay-up and RTM, and allow for outsourcing of components. The pultrusion process is particularly suited to high performance continuous fibre composites, which are the focus of this study. Figure 13 compares different composite manufacturing processes in terms of performance and units per annum. It shows that pultrusion processing of continuous fibre composites has the potential to outperform RTM processing in terms of both productivity (units per annum) and component performance. These factors are of utmost importance in trailer design and this suggests that pultrusion processing is worth exploring in this context. Moreover, the stiffened panel deign presented in this study is thought to be more manufacturable than other steel shape-optimised designs such as those presented by Kim [8] and Jin Gon [9], which have complex highly variable cross-sections along the length of the structure. The minimum variation cross-section shape used in the stiffened panel keeps the possibility of pultrusion processing open.

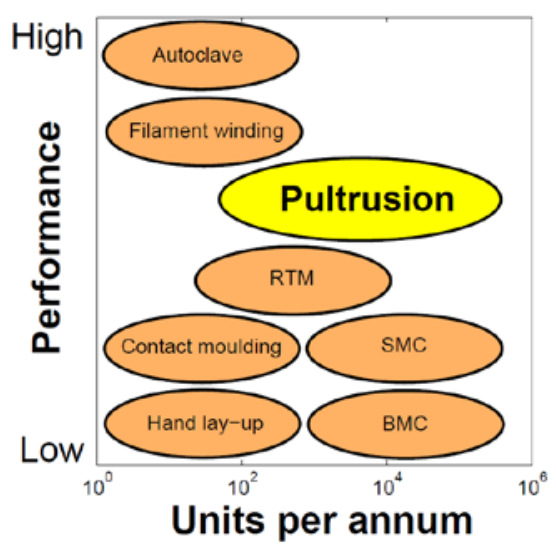

Figure 13. Composite manufacturing processes in terms of performance and units per annum, adapted from [23].

Finally, end-of-life considerations also need to be assessed in the design process as trailers must be returned to the manufacturer for recycling. Metals and natural materials are typically more desirable than polymer composites from a recyclability standpoint. However, the recyclability of composites, especially those made from continuous fibres, continues to be developed and expanded [24]. 


\section{LIMITATIONS AND FUTURE WORK}

The analysis presented in this study has notable limitations and significant work is still needed in realising a competitive lightweight composite trailer.

The structural analysis in the simplified stiffened panel model is centred on a critical static load. In practice, dynamic loads such as fatigue and impact that occur during trailer operation also need to be considered. Beam buckling should also be addressed. A thorough understanding of in-service loads is crucial for developing lightweight trailers that meet performance requirements without being unnecessarily stiff and strong in certain areas. More accurate knowledge of load requirements and environmental operating conditions can be used in conjunction with FE modelling. A more detailed and experimentally verified FE model would allow for composite solutions to be optimised further, which in turn provides more scope for weight reduction.

The simplified stiffened panel model used in the optimisation procedure in this study did not include trailer subcomponents and the joints between components. Joining of composite subcomponents to existing steel chassis beams is another important topic that could be explored in more detail. A potential future study could involve testing a range of established joining methods by adding composite sections to trailers already in-service and monitoring their performance. This would help characterise the most appropriate joining methods and their fatigue performance in truck trailers.

Detailed design and design for manufacture of advanced lightweight concepts to integrate into the broad solution presented here is another logical next step for research. For example, trailer decking formed with corrugated structures or isogrids could be good candidates for a detailed analysis in terms of optimising dimensions, materials and manufacturing routes.

Considering that the success of a lightweight composite trailer largely hinges on its economic viability, it would be desirable to undertake a detailed cost study. Such a study could investigate production and life cycle costs of composite trailers. A market survey to estimate the potential investment in lightweight trailers would also be useful.

\section{CONCLUSIONS}

The current conventional European $13.5 \mathrm{~m}$ long steel ladder-type trailer chassis has been refined over time through experience, rather than empirical data. There are improvements that could be made to the existing structure through a greater understanding of in-service loadings and hence this is the focus of other current research. An improved understanding of trailer inservice loadings, combined with the structural optimisation procedures introduced in this study could reduce chassis weight without altering existing materials.

More significant weight reductions are more likely to be realised through both shape and material optimisation. This has been demonstrated through a simplified numerical model of a holistic composite truck trailer chassis. While the stiffened-panel composite trailer structures presented here could be difficult and costly to produce with current composite manufacturing technologies, they may become increasingly viable with advancements in processing techniques such as pultrusion processing. A composite chassis formed of CFRP beams and 
a pultruded GFRP deck could drastically reduce overall trailer weight (by up to $1,326 \mathrm{~kg}$ or $67 \%$ ). However, the high material costs associated with CFRP dictate that a more economic approach is to use CFRP in the front end of the beams and GFRP in the rear end of the beams. FE modelling and optimisation has shown that this structure would reduce trailer weight significantly (by $940 \mathrm{~kg}$ or 47\%). Increasing the maximum allowable rear end displacement would allow for the most significant levels of weight reduction to be realised. It is evident from this study that a combination of structural optimisation and material selection in trailer chassis design allows for many different structural configurations to be analysed. This approach helps to rapidly assess potential novel trailer designs in terms of both mechanical performance and cost.

To reduce empty truck trailer mass in practice, applying lightweight composite materials to trailer subcomponents such trailer decking and side walls seems a logical way to begin. These strategies can be implemented more quickly by existing trailer manufacturers and for a minimal increase in cost. By adopting multiple subcomponent replacement strategies, similar levels of weight reductions can be achieved as with a 'clean-slate' chassis re-design. However, for a longer-term solution, more radical design changes will be needed to drastically reduce empty truck trailer weight.

\section{REFERENCES}

1. McKinnon, A. Life without trucks: the impact of a temporary disruption of road freight transport on a national economy. Journal of Business Logistics. 2006 2006/09/01;27(2):227-250. https://doi:10.1002/j.2158-1592.2006.tb00224.x

2. Galos, J., Sutcliffe, M., Cebon, D., et al. Reducing the energy consumption of heavy goods vehicles through the application of lightweight trailers: Fleet case studies [Article]. Transportation Research Part D: Transport and Environment. 2015;41:4049. https://doi:10.1016/j.trd.2015.09.010

3. Galos, J., Sutcliffe, M., Cebon, D. Design of a lightweight heavy goods vehicle trailer. European Transport Conference; Frankfurt: Association for European Transport; 2014.

4. Galos, J., Sutcliffe, M., Newaz, G. Design, fabrication and testing of sandwich panel decking for use in road freight trailers. Journal of Sandwich Structures and Materials. 2018;20(6):735-758. https://doi:10.1177/1099636216680153

5. Galos, J., Sutcliffe, M., Cebon, D., et al. Lightweighting road freight semi-trailers through the application of composites in trailer decking. ICCM International Conferences on Composite Materials (ICCM20); 19-24 July 2015; Copenhagen, Denmark.

6. Turner, M., Boyce, G. ROADLITE - Manufacture of a lightweight, cost effective, polymer composite road trailer. JSAE Annual Congress; 2005.

7. Verhaeghe, J. Introducing an affordable composite trailer to a conservative market: Materials Today; 2006. Available from: https://www.materialstoday.com/compositeapplications/features/introducing-an-affordable-composite-trailer-to-a/

8. Kim, J.G., Jang, G.W. Development of a lightweight frame for a 40-foot flatbed trailer by using CAE-based structural optimization. Proceedings of the Institution of Mechanical Engineers, Part D: Journal of Automobile Engineering. 2011 2011/05/01;225(5):643-652. https://doi:10.1177/0954407010395688

9. Jin, G.K, Min Su, Y. Optimal Design of Lightweight Frame for Heavy Flat-Bed Trailer by Using Taguchi Method. Transactions of the Korean Society of Mechanical Engineers - A. 2010 3;34(3):353-359. 
10. Galos, J., Sutcliffe, M., Newaz, G. Mechanical behaviour of phenolic coated Finnish birch plywood with simulated service damage. Wood Material Science and Engineering. 2017;12(5):307-315. https://doi:10.1080/17480272.2016.1218931.

11. Galos, J.L. Lightweight Composite Trailer Design: University of Cambridge; 2017. https://doi.org/10.17863/CAM.8922

12. Galos, J.L., Sutcliffe, M.P.F. Development of a structural optimisation methodology for use in the design of a composite semi-trailer chassis. ICCM International Conferences on Composite Materials (ICCM20); 20-25 August 2017 20-25 August; Xi'an, China.

13. Kural, K., Voskuijl, M., Fengnian, T., et al. Determination of representative loading conditions for effective semitrailer design. Transport. 2014 2014/10/02;29(4):363375. https://doi:10.3846/16484142.2014.982174

14. Pauwelussen, J., Visscher, J., Merts, M., et al. An integrated testing and model based design approach for semi-trailer weight reduction. 11th International Symposium on Heavy Vehicle Transportation Technology (HVTT11); 14-17 March; Melbourne, Australia: International Forum for Road Transport Technology; 2010.

15. Sturgess, T. SDC Trailers Ltd., personal communication, April 2014.

16. Aceves, C.M., Skordos, A.A., Sutcliffe, M.P.F. Design selection methodology for composite structures. Materials \& Design. 2008 2008/01/01/;29(2):418-426. doi: https://doi.org/10.1016/j.matdes.2007.01.014

17. Aceves, C.M., Sutcliffe, M.P.F., Ashby, M.F., et al. Design methodology for composite structures: A small low air-speed wind turbine blade case study. Materials \& Design (1980-2015). 2012 2012/04/01/;36:296-305. doi: https://doi.org/10.1016/j.matdes.2011.11.033

18. CES EduPack 2014. Granta Design, Camidge, UK; 2014.

19. Fiberline Composites, The Fiberline Design Manual; 2003.

20. Lawrence David lightweight aerodynamic double-deck trailer trial: Innovate UK; [cited 20191 April]. Available from: https://left.trl.co.uk/lawrence-david-limited/

21. Stephens, R.G., Babinsky, H. An Experimental Study on Truck Side-Skirt Flow. SAE International; 2016. https://doi:10.4271/2016-01-1593

22. Stephens, R.G., Stevens, P.R.R.J., Babinsky, H. A Method for Truck Underbody Aerodynamic Investigation. SAE International; 2016. https://doi:10.4271/2016-01$\underline{9020}$

23. Furness, J. Thermosetting Composites - Processing: AZO Materials; 2001 [cited 20191 April]. Available from: https://www.azom.com/article.aspx?ArticlelD=352

24. Pimenta, S., Pinho, S.T. Recycling carbon fibre reinforced polymers for structural applications: Technology review and market outlook [Article]. Waste Management. 2011;31(2):378-392. doi: 10.1016/j.wasman.2010.09.019.

\title{
ACKNOWLEDGEMENTS
}

The authors would like to acknowledge the financial support from the members of the Centre for Sustainable Road Freight and from the Engineering and Physical Sciences Research Council (Grant Reference EP/K00915X/1).

\author{
NOMENCLATURE \\ Roman symbols \\ $b$ - section width \\ $D$ - stiffness matrix terms \\ $E-$ Young's modulus \\ $G$ - shear modulus \\ $h$ - beam height \\ $L$ - unsupported span length
}


$N$ - forces per unit length

$t\left(t_{f r}, t_{r}, t_{w}\right)-$ thickness (front flange, rear flange, web)

\section{Greek symbols}

$\partial$ - deflection

$\sigma\left(\sigma_{u}\right)$ - bending stress (ultimate stress)

$\tau\left(\tau_{u}\right)$ - shear stress (ultimate shear stress)

$\varepsilon$ - engineering strain

$\gamma_{12}-$ shear membrane strain

$K$ - curvature

$\kappa_{12}$ - shear membrane twist

$\rho$ - density

\section{Acronyms / Abbreviations}

$\mathrm{Al}$ - Aluminium

BMC - Bulk Moulding Compound

CFRP - Carbon Fibre Reinforced Polymer

FE - Finite Element

$\mathrm{FI}$ - Failure Index

GFRP - Glass Fibre Reinforced Polymer

RTM - Resin Transfer Moulding

SMC - Sheet Moulding Compound

UDL - Uniformly Distributed Load

\section{APPENDICES}

\section{Appendix 1: General shell section approximation of trailer deck}

The simplified trailer deck was modelled using a general shell section, defined by Eq. (A1), which can be expanded to Eq. (A2). The 1, 2 and 3 directions in these equations correspond to the $x, z$ and $y$ directions, respectively, as shown in Figure 6 . In these equations, the direct membrane terms come first, then the shear membrane term, then the direct and shear bending terms, with six terms in all. Note that engineering measures of shear membrane strain $\left(\gamma_{12}\right)$ and twist $\left(\kappa_{12}\right)$ are used in Abaqus.

$$
\{N\}=[D]\{E\}
$$

where

$\{\mathbf{N}\}$ are the membrane forces per unit length and bending moments per unit le

$\{E\}$ are the generalised section strains in the shell, and;

[D] is the section stiffness matrix.

$$
\left\{\begin{array}{l}
N_{11} \\
N_{22} \\
N_{12} \\
M_{11} \\
M_{22} \\
M_{12}
\end{array}\right\}=\left[\begin{array}{llllll}
D_{11} & D_{12} & D_{13} & D_{14} & D_{15} & D_{16} \\
D_{21} & D_{22} & D_{23} & D_{24} & D_{25} & D_{26} \\
D_{31} & D_{32} & D_{33} & D_{34} & D_{35} & D_{36} \\
D_{41} & D_{42} & D_{43} & D_{44} & D_{45} & D_{46} \\
D_{51} & D_{52} & D_{53} & D_{54} & D_{55} & D_{56} \\
D_{61} & D_{62} & D_{63} & D_{64} & D_{65} & D_{66}
\end{array}\right]\left\{\begin{array}{l}
\varepsilon_{11} \\
\varepsilon_{22} \\
\gamma_{12} \\
\kappa_{11} \\
\kappa_{22} \\
\kappa_{12}
\end{array}\right\}
$$


The terms of the stiffness matrices for the two different structural decks are defined in Eq. (A3) and Eq. (A4).

$$
\begin{gathered}
{[\mathbf{D}]_{1}: D_{22}=1.7 \times 10^{5} \frac{\mathrm{N}}{\mathrm{mm}},} \\
D_{55}=3.2 \times 10^{7} \frac{\mathrm{N}}{\mathrm{mm}}, D_{11}=D_{33}=D_{44}=D_{66} \approx 0 \\
{[\mathbf{D}]_{2}: D_{11}=D_{22}=1.0 \times 10^{6} \frac{\mathrm{N}}{\mathrm{mm}},} \\
D_{44}=D_{55}=3.0 \times 10^{8} \frac{\mathrm{N}}{\mathrm{mm}}, D_{33}=D_{66} \approx 0
\end{gathered}
$$

